\title{
SVOC Concentrations in House dust and Residential Environment in Japanese Houses
}

\author{
Hoon KIM ${ }^{1, *}$, Yohei INABA ${ }^{1}$, Kanae BEKKI ${ }^{1}$, Motoya HAYASHI ${ }^{1}$, Kenichi AZUMA ${ }^{2}$ and Naoki KUNUGITA ${ }^{3}$ \\ ${ }^{1}$ National Institute of Public Health, Saitama, Japan \\ ${ }^{2}$ Kindai University, Osaka, Japan \\ ${ }^{3}$ University of Occupational and Environmental Health, Fukuoka, Japan
}

\begin{abstract}
This study aims to investigate the relevance of between SVOC concentrations in house dust and living environments. Using the newly proposed dust collecting and SVOC analysis method, we determined concentrations of the nine SVOC substances by dust size and made simultaneously the questionnaire about residential environments. Collected dusts were screened with sieves and then analyzed on nine components (DEP, DMP, BBP, DEHP, DINP, DBP, DNOP, DIDP, DIBP) by LC/MS/MS method. The results leaded to selecting less than $100 \mu \mathrm{m}$ and $100-250 \mu \mathrm{m}$ as the target size of dusts to be investigated intensively by considering the concentration distribution and the oral intake of humans. DEHP and DINP accounted for 96 to $97 \%$ of determined amount of SVOC and only the small amounts in the other seven components were detected. There was no significant difference in the component ratio depending on particle size. Significant difference was obtained between a few substances of SVOC and several living environment items.
\end{abstract}

\section{Introduction}

Several phthalate esters are added as plasticizers to increase flexibility and moldability of plastic products, and classified as SVOC (semi-volatile organic compounds) with a high boiling point. These are widely used in our life from building materials to toys, children's goods, daily necessaries and cosmetics. It is said that many SVOC substances are hardly present in the air but rather on the surface of the objects and dust etc. since it has low vapor pressure and strong adsorptivity.

There is also a possibility of endocrine disruption and relevance to asthma and allergosis of children [1]. Furthermore, an increase in the usage of products containing SVOC ingredients and long-term contamination due to their persistent property are reinforcing concerns about health effects [2] [3].

This study aims to investigate the actual condition of SVOC concentration in house dust and to ascertain the
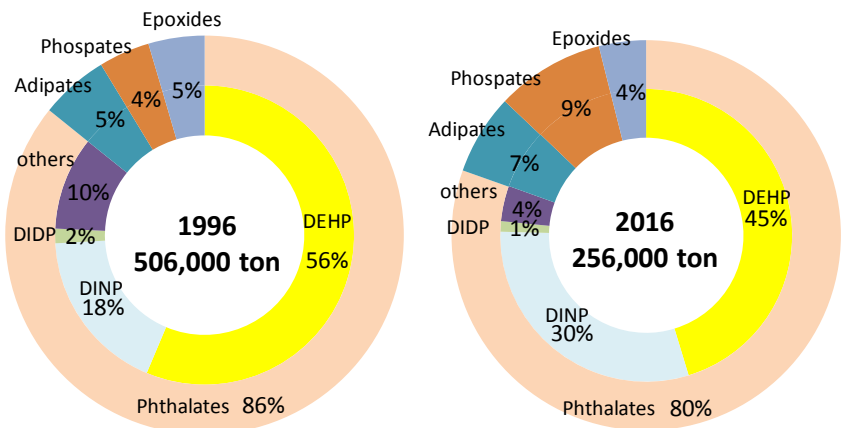

Fig 1. Production amount and composition ratio of plasticizer in Japan [4]. relevance of between them and living environments.

As a preliminary test, dusts were collected in ten houses and a detailed chemical analysis was conducted for four particle sizes. Based on the results, two particle sizes were selected to be examined intensively and then the determination of SVOC concentrations was conducted for the dusts collected in approximately 60 houses. Simultaneously we made the questionnaires about residential environments.

\section{Methods}

\subsection{Questionnaire survey}

The questionnaire concerning living environments included family characteristics and health conditions, house outline, indoor and surrounding environments, and details of daily life etc. Bivariate analysis was performed with the significance level $5 \%$ for correlation between SVOC concentrations and living environments.

\subsection{Dust collection and size selection}

There has been no unified method to collect house dust, and a few collecszting methods have been proposed. In this study, we conducted a background and blank test of three types of filters and selected the PET - nonwoven fabric filter as considering the applicability in the field.

In practice the dust accumulated in the vacuum cleaner as a backup specimen as well as filter collection in the field was collected since sufficient dust quantity

\footnotetext{
* Corresponding author: kimhoon@niph.go.jp
} 
should be ensured to classify dust sizes and to determine the chemical concentrations. For the preliminary study, ten houses provided their house dust and the dusts were sieved into the four particle sizes of less than $100 \mu \mathrm{m}$, $100-250 \mu \mathrm{m}, 250-500 \mu \mathrm{m}$ and more than $500 \mu \mathrm{m}$. For one dust specimen, from $n=5$ to 7 samples were prepared by each particle size, and the concentration distribution and deviation were investigated. The preliminary test resulted in selecting the two dust size of less than $100 \mu \mathrm{m}$ and $100-250 \mu \mathrm{m}$ and then dusts of 63 houses were analyzed for these two particle sizes. The outlines of the houses (in Fig. 2) showed the data of 71 houses that gave the cooperation for our research, and there were 59 (in less than $100 \mu \mathrm{m}$ ) and 63 (in $100-250 \mu \mathrm{m}$ ) dust samples respectively available for chemical analysis in the final analysis.

\subsection{Chemical analysis}

It has been difficult to quantify DINP and DIDP by using usual GC-MS method since the method spreads broadly saw-like low peaks on chromatograph for the both sub stances. We examined newly the method of solvent extraction-LC-MS/MS and could quantify stably the nine SVOC substances (in Fig. 3) -DEP(Diethyl phthalate), DMP(Dimethyl phthalate), BBP(Butyl Benzyl Phthalate), DEHP(Di(2-ethylhexyl)phthalate), DINP(Diisononyl phthalate), DBP(Dibutyl phthalate), DNOP(Di-n-octyl phthalate), DIDP(Diisodecyl phthalate), DIBP(Diisobutyl Phthalate)-.

\section{Result}

\subsection{Residential environments}

Most of the houses are in urban area, in detail 45 houses were in Kanto region (near Tokyo), 15 ones in Tohoku, 6 ones in Kyushu and 5 ones in Hokkaido.

In Fig. 2, for the cooling and heating system, the room air conditioners made up the majority in living rooms, main bedrooms, and the children's rooms. As other heating systems at living room, oil stove / fan heater accounted for $25 \%$ (18 cases), floor heating 18\% (13 cases), electric carpet and electric kotatsu did 11\% (8 cases) respectively. In the case of main bedroom, no heating was reported as $11 \%$ ( 8 cases), oil stove / fan heater was 7 cases, electric stove / fan heater was used at 4 rooms. Children's rooms were not much different from main bedrooms and showed the same breakdown.

At both living and bed rooms, wood floors accounted for the largest proportion of 60 to $70 \%$ and a lot of rooms were carpeted. About $30 \%$ (21 cases) used carpets at the living room, and the percentage at the main bedrooms was $11 \%$ ( 8 cases). In addition, there were a small number of straw mat, linoleum and vinyl sheets.

For the wall material, there was not a little of difference among living room, main bedroom and children's room, and the ratio of plastered walls at living room was slightly high. The ratio of wallpapers was close to $90 \%$ as vinyl or paper accounting for a half of the materials. Only four houses had a wood-based wall finish.

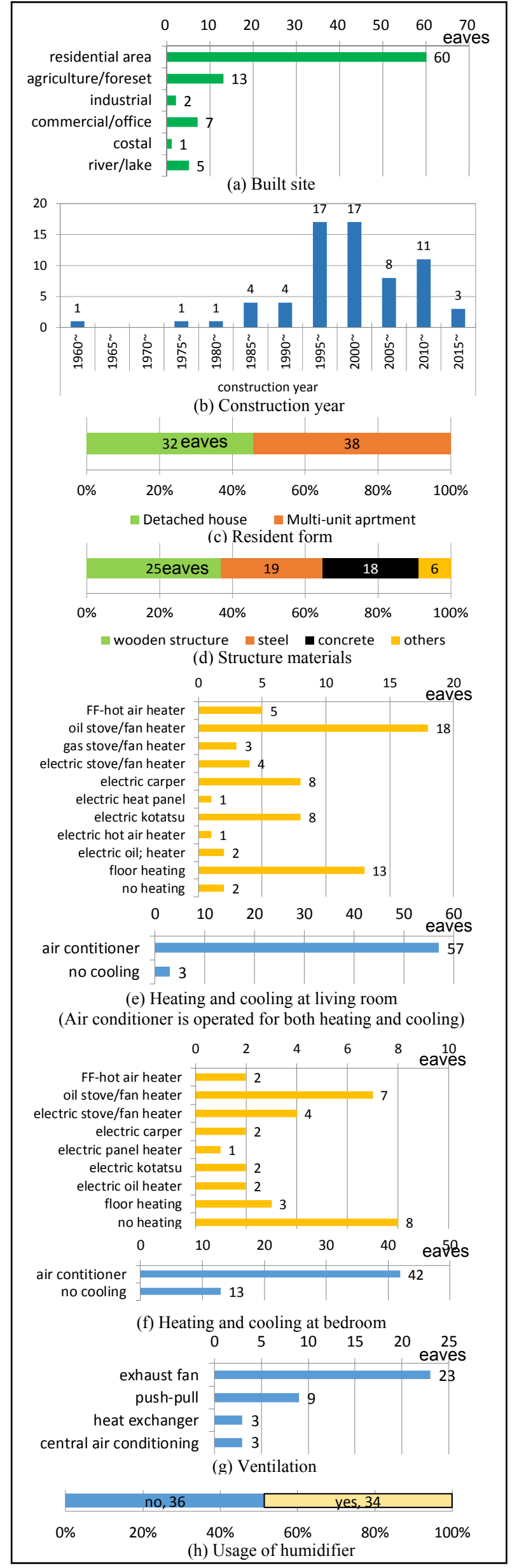

Fig 2. Overview of the houses. 


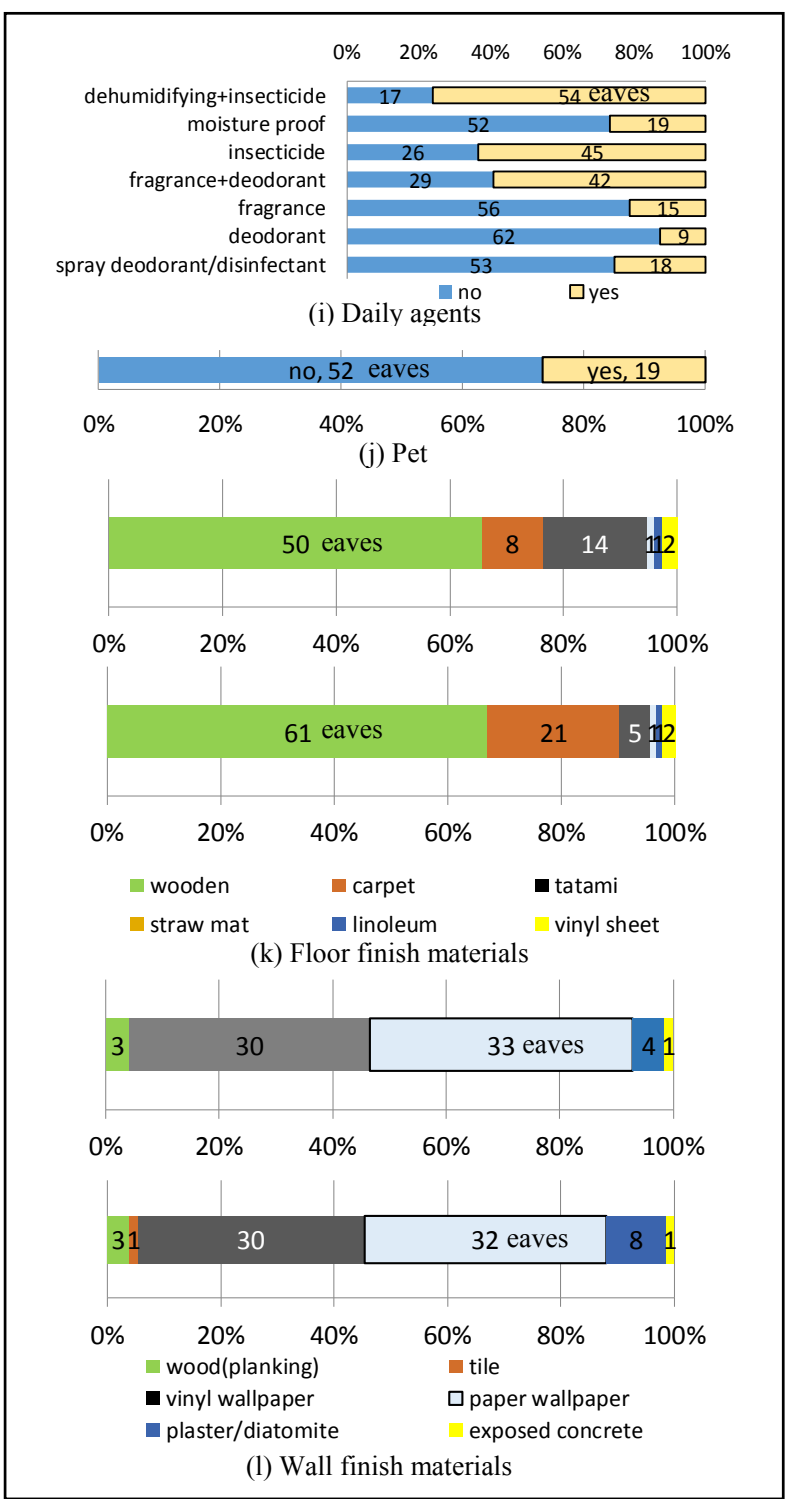

Fig 2. Overview of the houses. (sequel)

\subsection{Preliminary test for $\mathbf{1 0}$ house dust}

Table 1 shows a part of results of the preliminary study.

There is a substantial difference in determined SVOC amounts and components depending on houses. BBP, DIBP, DBP, DEHP and DINP were detected in all houses, and DIDP and DNOP were in large variation by houses. DEHP accounted for $70-80 \%$ of the total SVOC, and DINP followed as $10-20 \%$. The two substances accounted for $90 \%$ or more as ratio. BBP, DNOP, DMP and DEP were minute amount or below the quantitative limit.

The results leaded to selecting less than $100 \mu \mathrm{m}$ and $100-250 \mu \mathrm{m}$ as the target size of dusts to be investigated intensively by considering the concentration distribution and the oral intake of humans.

\subsection{SVOC concentrations in house dusts}

SVOC concentrations and component ratio of SVOC concentrations in house dusts for the two particle sizes were shown in Table 2 and in Figure 4. 59 specimens in less than $100 \mu \mathrm{m}$ and 63 specimens in $100-250 \mu \mathrm{m}$ were

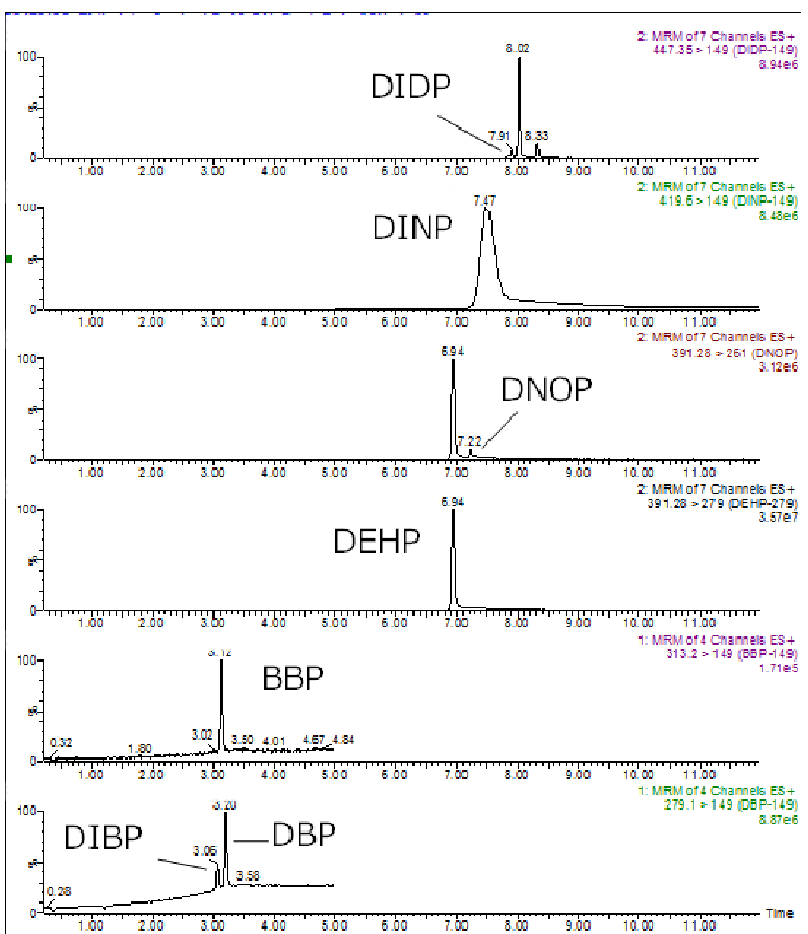

Fig 3. Chromatogram of SVOCs in dust (Solvent extraction, LC-MS/MS).

effectively determined. The average of the total amount of SVOC (SUM) was $1,983 \mu \mathrm{g} / \mathrm{g}$ in dusts of the particle size of less than $100 \mu \mathrm{m}$, and 3,028 $\mu \mathrm{g} / \mathrm{g}$ in $100-250 \mu \mathrm{m}$. In the component ratio, DEHP accounted for 83 to $84 \%$ of SUM and DINP was $13 \%$. Considering other existing researches and the domestic production amount of plasticizer, it was considered to be a reasonable value. Consequently the two substances accounted for 96 to $97 \%$ of SUM and only small amounts in the other seven components were detected.

\section{Discussion}

Correlation analysis (in Table 3) showed there was no significant difference between the component ratio of SVOC and dust sizes. It was observed lower concentration of DEHP $(100-250 \mu \mathrm{m})$ and SUM (100$250 \mu \mathrm{m})$ at housing that their location was in a residential area. Significant difference was also found for DEHP, DINP, SUM concentrations with house ages and residence years in dusts of 100-250 $\mu \mathrm{m}$. The longer the house ages and residence years, the higher the concentrations were detected. In the case of using wooden floor, it made a decrease tendency in DEHP, DINP, SUM concentrations. In the other hand, PVC floor sheet increased significantly DEHP, SUM concentrations.

Significant difference, however, was not obtained from kinds of wall and ceiling material, frequency of running a vacuum cleaner, cleaning method and having a pet.

\section{Conclusions}

In order to assess the intake amount and human health risk of SVOC from indoor air, house dust, transdermal absorption, this report indicated that it is important 
Table 1. Examples of SVOC determination in house dust by particle size in the preliminary study (less than 100, 100-250, 250-500, more than 500 $\mu \mathrm{m}$ ).

\begin{tabular}{|c|c|c|c|c|c|c|c|c|c|c|c|c|c|c|c|c|c|c|c|c|c|c|c|c|c|c|c|}
\hline \multicolumn{2}{|c|}{ House A } & \multicolumn{20}{|c|}{ Amounts $(\mu \mathrm{g} / \mathrm{g})$} & & & & & & \\
\hline \multirow[b]{2}{*}{ size $(\mu \mathrm{m})$} & \multirow[b]{2}{*}{ samples } & \multicolumn{3}{|c|}{ BBP } & \multicolumn{3}{|c|}{ DIBP } & \multicolumn{3}{|c|}{ DBP } & \multicolumn{2}{|c|}{ DEHP } & \multicolumn{3}{|c|}{ DINP } & \multicolumn{3}{|c|}{ DIDP } & \multicolumn{3}{|c|}{ DNOP } & \multicolumn{3}{|c|}{ DMP } & \multicolumn{3}{|c|}{ DEP } \\
\hline & & Mean & \pm & $\mathrm{SL}$ & Mean & \pm & SD & Mean & \pm & SD & Mean & $\pm \quad S D$ & Mean & \pm & $\mathrm{SD}$ & Mean & \pm & SD & Mean & \pm & $\mathrm{SD}$ & Mean & \pm & SD & Mean & \pm & $\mathrm{SD}$ \\
\hline$<500$ & 5 & 12.1 & \pm & 0.9 & & $5 \pm$ & 0.6 & 14.1 & \pm & 2.3 & 640 & \pm 96 & 469 & \pm & 48 & 7.9 & \pm & 12.1 & 0.4 & \pm & & & \pm & & & $0 \pm$ & 0 \\
\hline $250-500$ & 5 & 23.5 & \pm & 6.2 & 4.9 & $9 \pm$ & 1.0 & 18.4 & \pm & 2.6 & 1,076 & \pm 517 & 724 & \pm & 106 & 4.7 & \pm & 1.4 & 0.6 & \pm & 1.4 & & \pm & 0 & & $0 \pm$ & 0 \\
\hline $100-250$ & 5 & 24.9 & \pm & 1.2 & 3.6 & $5 \pm$ & 1.1 & 21.9 & \pm & 2.3 & 1,145 & \pm 95 & 848 & \pm & 32 & 4.7 & \pm & 0.2 & 0.0 & \pm & 0.0 & & \pm & 0 & & $0 \pm$ & 0 \\
\hline $100<$ & 5 & 20.5 & \pm & 0.6 & 2.0 & $0 \pm$ & 1.2 & 20.8 & \pm & 1.6 & 1,274 & \pm 86 & 509 & \pm & 304 & 3.9 & \pm & 2.3 & 0.0 & \pm & 0.0 & & $0 \pm$ & 0 & & $0 \pm$ & 0 \\
\hline \multicolumn{2}{|c|}{ House C } & \multicolumn{20}{|c|}{ Amounts $(\mu \mathrm{g} / \mathrm{g})$} & & & & & & \\
\hline & & \multicolumn{3}{|c|}{ BBP } & \multicolumn{3}{|c|}{ DIBP } & \multicolumn{3}{|c|}{ DBP } & & DEHP & \multicolumn{3}{|c|}{ DINP } & \multicolumn{3}{|c|}{ DIDP } & \multicolumn{3}{|c|}{ DNOP } & \multicolumn{3}{|c|}{ DMP } & \multicolumn{3}{|c|}{ DEP } \\
\hline 粒径別 $(\mu \mathrm{m})$ & samples & Mean & \pm & $\mathrm{SD}$ & Mean & \pm & SD & Mean & \pm & $\mathrm{SD}$ & Mean & $\pm \quad \mathrm{SD}$ & Mean & \pm & SD & Mean & \pm & SD & Mean & \pm & $\mathrm{SD}$ & Mean & \pm & SD & Mean & $7 \pm$ & $\mathrm{SL}$ \\
\hline$<500$ & 5 & 1.4 & $4 \pm$ & $=0.2$ & 7.6 & $5 \pm$ & 2.2 & 27.4 & \pm & 3.4 & 1,759 & \pm 219 & 256 & \pm & 219 & 260.5 & \pm & 30.8 & 0.2 & \pm & & 0.0 & $0 \pm$ & 0.0 & 0.1 & $1 \pm$ & 0.1 \\
\hline $250-500$ & 5 & 1.6 & $5 \pm$ & $=0.5$ & 9.7 & $7 \pm$ & 1.6 & 40.6 & \pm & 9.4 & 2,850 & \pm 739 & 304 & \pm & 274 & 267.0 & \pm & 14.7 & 0.4 & \pm & 0.8 & 0.1 & $1 \pm$ & 0.3 & & $4 \pm$ & $=0.6$ \\
\hline $100-250$ & 5 & 1.2 & $2 \pm$ & $=0.3$ & 9.5 & $5 \pm$ & 1.2 & 75.8 & \pm & 29.1 & 4,694 & \pm 911 & 330 & \pm & 42.6 & 243.8 & \pm & 38.0 & 0.0 & \pm & 0.0 & 0.0 & $0 \pm$ & 0.0 & 0.5 & $5 \pm$ & $=1.0$ \\
\hline $100<$ & 5 & 1.8 & $8 \pm$ & $=0.3$ & 8.6 & $6 \pm$ & 0.6 & 50.1 & \pm & 4.9 & 2,042 & \pm 97.3 & 123 & \pm & 18.0 & 238.6 & \pm & 10.9 & 0.0 & \pm & 0.0 & 0.0 & $0 \pm$ & 0.0 & 0.1 & $1 \pm$ & $=0.1$ \\
\hline
\end{tabular}

to investigate intensively the two dust sizes of less than $100 \mu \mathrm{m}$ and 100 $250 \mu \mathrm{m}$ when considering the concentration distribution and the oral intake of human.

DEHP accounted for 83 to $84 \%$ of SUM and DINP was $13 \%$ by weight ratio to whole SVOC components, and the two substances accounted for 96 to $97 \%$ of SUM, and only the small amounts were detected in the other seven components.

Significant difference was obtained between a few substances of SVOC and several living environmental items such as residential location, type of floor material, years after construction and/or residence, fragrance, spray type deodorant and disinfectant.

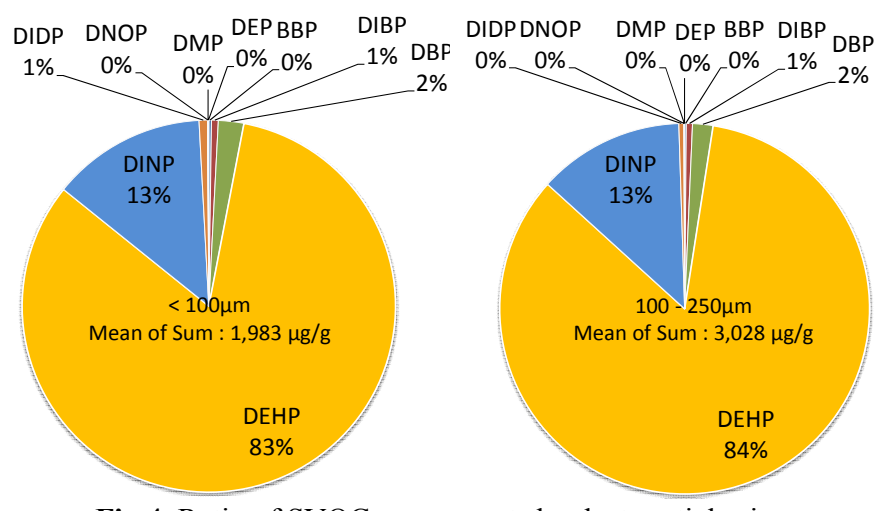

Fig 4. Ratio of SVOC components by dust particle size

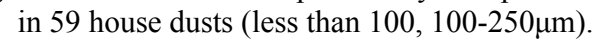

This work was supported partly by Health Labour Sciences Research Grant 「H28-health/crisis-007」 and MEXT KAKENHI Grant Number 「16H04468」.

\section{References}

1. C. Bornehag, J. Sundell, C. J. Weschler, : The Association between Asthma and Allergic Symptoms in Children and Phtalates in House Dust: A Nested Case-Control Study, Environmental Health Perspectives, Vol. 112, No. 14, pp 13931397 (2004)

2. EHHI : The Plastics Problem -Plastics that may be harmful to
Table 3. Correlation analysis between SVOC concentrations in house dusts and residential environments (showed only variables with a significant difference)

\begin{tabular}{|c|c|c|c|c|c|}
\hline & objective variable & explanatory variable & estimated & $\mathrm{t}$-value & $\begin{array}{c}\mathrm{p} \text {-value } \\
(\text { Prob }>|\mathrm{t}|)\end{array}$ \\
\hline \multirow{3}{*}{ built area } & DEHP $100-250 \mu \mathrm{m}$ & residential area & -1846 & -2.42 & 0.018 \\
\hline & DINP $100-250 \mu \mathrm{m}$ & river/lake & 362 & 2.10 & 0.040 \\
\hline & SUM $100-250 \mu \mathrm{m}$ & residential area & -1985 & -2.45 & 0.017 \\
\hline surroundings & DINP $100-250 \mu \mathrm{m}$ & electrical train line & 223 & 2.15 & 0.035 \\
\hline \multirow{3}{*}{ house outline } & DEHP $100-250 \mu \mathrm{m}$ & house age & 81 & 2.74 & 0.008 \\
\hline & DINP $100-250 \mu \mathrm{m}$ & residence year & 100 & 3.13 & 0.003 \\
\hline & SUM $100-250 \mu \mathrm{m}$ & house age & 88 & 2.79 & 0.007 \\
\hline \multirow{8}{*}{$\begin{array}{l}\text { floor finish } \\
\text { at living room }\end{array}$} & DEHP $<100 \mu \mathrm{m}$ & LF-wooden floor & -1430 & -2.71 & 0.009 \\
\hline & DEHP $<100 \mu \mathrm{m}$ & LF-vinyl sheet & 2128 & 2.08 & 0.042 \\
\hline & DEHP $100-250 \mu \mathrm{m}$ & LF-wooden floor & -3389 & -5.07 & $<.0001$ \\
\hline & DEHP $100-250 \mu \mathrm{m}$ & $\begin{array}{l}\text { LF-tatami } \\
\text { (Japanese straw mat) }\end{array}$ & 2144 & 2.06 & 0.044 \\
\hline & DEHP $100-250 \mu \mathrm{m}$ & LF-vinyl sheet & 3727 & 2.34 & 0.023 \\
\hline & SUM $100-250 \mu \mathrm{m}$ & LF-wooden floor & -3590 & -5.04 & $<.0001$ \\
\hline & SUM $100-250 \mu \mathrm{m}$ & $\begin{array}{l}\text { LF-tatami } \\
\text { (Japanese straw mat) }\end{array}$ & 2333 & 2.11 & 0.039 \\
\hline & SUM $100-250 \mu \mathrm{m}$ & LF-vinyl sheet & 3701 & 2.17 & 0.034 \\
\hline \multirow{3}{*}{$\begin{array}{l}\text { floor finish } \\
\text { at bedroom }\end{array}$} & DEHP $<100 \mu \mathrm{m}$ & BF-vinyl sheet & 2128 & 2.08 & 0.042 \\
\hline & DEHP $100-250 \mu \mathrm{m}$ & BF-vinyl sheet & 3727 & 2.34 & 0.023 \\
\hline & SUM $100-250 \mu \mathrm{m}$ & BF-vinyl sheet & 3701 & 2.17 & 0.034 \\
\hline \multirow{2}{*}{$\begin{array}{l}\text { wall finish } \\
\text { at living room }\end{array}$} & DEHP $100-250 \mu \mathrm{m}$ & LW-plaster/diatomite & 2000 & 2.24 & 0.028 \\
\hline & SUM $100-250 \mu \mathrm{m}$ & LW-plaster/diatomite & 2133 & 2.25 & 0.028 \\
\hline \multirow{3}{*}{$\begin{array}{l}\text { cooling and } \\
\text { heating }\end{array}$} & DINP $<100 \mu \mathrm{m}$ & oil burner/fan heater & 218 & 2.25 & 0.028 \\
\hline & SUM $<100 \mu \mathrm{m}$ & FF-hot air heater & 2561 & 2.33 & 0.023 \\
\hline & DINP $100-250 \mu \mathrm{m}$ & oil burner/fan heater & 293 & 2.05 & 0.045 \\
\hline \multirow{2}{*}{ ventilation } & DEHP $100-250 \mu \mathrm{m}$ & exhause fan & 1676 & 2.85 & 0.006 \\
\hline & SUM $100-250 \mu \mathrm{m}$ & exhause fan & 1796 & 2.87 & 0.006 \\
\hline \multirow[b]{2}{*}{ groceries } & SUM $<100 \mu \mathrm{m}$ & fragrance & -954 & -2.03 & 0.047 \\
\hline & DINP $100-250 \mu \mathrm{m}$ & $\begin{array}{l}\text { spray deodorant } \\
\cdot \text { disinfectant }\end{array}$ & 198 & 2.05 & 0.045 \\
\hline
\end{tabular}

children and reproductive health-, Environment \& Human Health, Inc.(EHHI) (2008)

3. European Union : Official Journal of the European Union Commission Delegated Directive (EU) 2015/863 of 31 March 2015-, L 137/10-12 (2015)

4. Vinyl Environmental Council : Breakdown of Plasticizer production amount, http://www.vec.gr.jp/lib/lib2_6.html\#cc (accessed on 2018.09.15.) 